Abstract Word Count: 252

Introduction Word Count: 575/1000

Discussion Word Count: 1688/2000

Total Word Count: 4758/6000

Tables/Figures: 6/6

Number of References: 76/50

Date of Submission: 10/07/2016

Date of Resubmission: 01/03/2017

\title{
Hypothalamic-Pituitary-Adrenal Axis Genetic Variation and Early Stress Moderates Amygdala Function
}

Christina R. Di Iorio, ${ }^{1}$ Caitlin E. Carey, ${ }^{1}$ Lindsay J Michalski, ${ }^{1}$ Nadia S. Corral-Frias, ${ }^{2}$ Emily Drabant Conley, ${ }^{3}$ Ahmad R. Hariri, ${ }^{4}$ Ryan Bogdan ${ }^{1,5-7}$

${ }^{1}$ BRAIN Lab, Department of Psychology, Washington University in St. Louis, St. Louis, MO, USA

${ }^{2}$ Department of Psychiatry, Washington University in St. Louis, St. Louis, MO, USA ${ }^{3} 23$ andMe

${ }^{4}$ Department of Psychology and Neuroscience, Duke University, Durham, NC, USA

${ }^{5}$ Neurosciences Program, Division of Biology and Biomedical Sciences, Washington University in St. Louis, St. Louis, MO, USA

${ }^{6}$ Molecular Genetics and Genomics Program, Division of Biology and Biomedical Sciences, Washington University in St. Louis, St. Louis, MO, USA

${ }^{7}$ Human and Statistical Genetics Program, Division of Biology and Biomedical Sciences, Washington University in St. Louis, St. Louis, MO, USA

Corresponding authors: Christina Di Iorio \& Ryan Bogdan

WUSTL, Psych Bldg, CB 1125

One Brookings Drive

St. Louis, MO 63130

Phone: 617-407-5645; email: crdiiorio@wustl.edu, rbogdan@wustl.edu, 


\title{
DIIORIO HPA BIOLOGICALLY-INFORMED MULTILOCUS PROFILE 2
}

\begin{abstract}
Early life stress may precipitate psychopathology, at least in part, by influencing amygdala function. Converging evidence across species suggests that links between childhood stress and amygdala function may be dependent upon hypothalamic-pituitary-adrenal (HPA) axis function. Using data from collegeattending non-Hispanic European-Americans ( $\mathrm{n}=308)$ who completed the Duke Neurogenetics Study, we examined whether early life stress (ELS) and HPA axis genetic variation interact to predict threat-related amygdala function as well as psychopathology symptoms. A biologically-informed multilocus profile score (BIMPS) captured HPA axis genetic variation (FKBP5 rs1360780, CRHR1 rs110402; NR3C2 rs5522/rs4635799) previously associated with its function (higher BIMPS are reflective of higher HPA axis activity). BOLD fMRI data were acquired while participants completed an emotional face matching task. ELS and depression and anxiety symptoms were measured using the childhood trauma questionnaire and the mood and anxiety symptom questionnaire, respectively. The interaction between HPA axis BIMPS and ELS was associated with right amygdala reactivity to threat-related stimuli, after accounting for multiple testing (empirical-p=0.016). Among individuals with higher BIMPS (i.e., the upper 21.4\%), ELS was positively coupled with threat-related amygdala reactivity, which was absent among those with average or low BIMPS. Further, higher BIMPS were associated with greater self-reported anxious arousal, though there was no evidence that amygdala function mediated this relationship. Polygenic variation linked to HPA axis function may moderate the effects of early life stress on threat-related amygdala function and confer risk for anxiety symptomatology. However, what, if any, neural mechanisms may mediate the relationship between HPA axis BIMPS and anxiety symptomatology remains unclear.
\end{abstract}

Keywords: Amygdala; early life stress; anxiety; depression; gene; HPA; cortisol 


\section{DIIORIO HPA BIOLOGICALLY-INFORMED MULTILOCUS PROFILE 3}

\subsection{Introduction}

It is undeniable that exposure to early life stress (ELS) predicts various forms of psychopathology (Green et al., 2010). However, the biological correlates contributing to this association are unclear. Research across species shows that ELS may, in part, promote psychopathology by influencing amygdala function (Lupien et al., 2009). The amygdala is critical for establishing the emotional significance of stimuli and enacting changes in physiological arousal and behavioral vigilance in response to provocation (Davis and Whalen, 2001). Nearly every form of psychopathology has been linked to abnormal amygdala function; most consistently, increased amygdala reactivity to threat has been found in stress-related disorders (Hariri, 2015; Shackman et al., 2016). ELS also predicts increased threat-related amygdala reactivity and amygdala-dependent behaviors (e.g., startle response, emotional memory, attentional bias toward threat; (Lupien et al., 2009; Tottenham and Sheridan, 2009), suggesting that ELS-related differences in amygdala reactivity and related behavior are a promising mechanism through which ELS increases psychopathology risk.

Stress- and psychopathology-related differences in amygdala function may be partially driven by associated hypothalamic-pituitary-adrenal (HPA) axis dysfunction (de Kloet et al., 2005). Indeed, amygdala reactivity is positively correlated with endogenous cortisol and pharmacologic agonism of the HPA axis potentiates amygdala reactivity in mouse and man (Bogdan et al., 2016). Collectively, these data suggest that variability in amygdala function may be related to ELS exposure, with independent converging lines of evidence suggesting that HPA axis function, which is highly heritable, (Federenko et al., 2004) temporally stable (Marquez et al., 2005), and disrupted by early life stress exposure (Essex et al., 2011) may be a key factor underlying this relationship. Lastly, multiple genetic association studies have identified polymorphisms coding for HPA axis-related proteins that are associated with functional consequences in the HPA axis (Table 1; Supplementary Material; (Derijk et al., 2008)) and predict stress-related psychopathology (Heim and Binder, 2012), as well as differences in amygdala function 


\section{DIIORIO HPA BIOLOGICALLY-INFORMED MULTILOCUS PROFILE 4}

(Bogdan et al., 2016). These findings suggest that vulnerability to the effects of ELS may depend on genetically-conferred differences in HPA axis function.

Using data from the Duke Neurogenetics Study (DNS), which assesses a wide range of behavioral, experiential, and biological phenotypes among young adult college students, the present study examined whether a biologically informed multilocus profile score (BIMPS) reflecting functionallyrelevant genetic variation in the HPA axis (Table 1) predicts amygdala function as well as psychopathology symptoms in the context of ELS. Our BIMPS approach aggregates genetic influence within the HPA axis that has previously been associated with HPA axis function, which may be more consistent with the resolution at which BOLD fMRI and behavioral genetics research is conducted than single SNP analyses. Such polygenic approaches are expected to provide more power by including polymorphisms of small effect that may only collectively significantly contribute to variance. Indeed, prior BIMPS approaches suggest that such profiles can significantly predict variability in neural and psychiatric phenotypes when individual polymorphisms do not (Nikolova et al., 2011; Pearson-Fuhrhop et al., 2014; Stice et al., 2012). Further, by using a biologically-informed approach with a priori rationale for including functional variants in the multilocus profile, as opposed to summary statistics reflecting relationships to a particular disorder, our results are more directly interpretable alongside other HPA axisrelated research (Bogdan et al., 2016; Nikolova et al., 2011). Consistent with prior work evaluating single polymorphisms (White et al., 2012), we predicted that genetic variation associated with increased HPA axis activity would predict elevated threat-related amygdala reactivity and anxiety and mood symptomatology among those exposed to relatively elevated ELS. 


\section{DIIORIO HPA BIOLOGICALLY-INFORMED MULTILOCUS PROFILE 5}

\subsection{Methods and Materials}

\subsection{Participants}

Non-Hispanic European/European-American participants $(n=325)$ of the Duke Neurogenetics Study (DNS) with fMRI and genetic data that were processed by January 2014 were available for analyses. Participants provided written informed consent to a study protocol approved by the Duke University institutional review board and were in general good health and free of DNS exclusions, including: 1) medical diagnosis of cancer, stroke, diabetes requiring insulin treatment, chronic kidney or liver disease, or lifetime psychotic symptoms; 2) use of psychotropic, glucocorticoid, or hypolipidemic medication; 3) conditions affecting cerebral blood flow and metabolism (e.g., hypertension); and 4) contraindications to MRI scanning. DSM-IV psychiatric disorders were assessed with the lifetime electronic Mini International Neuropsychiatric Interview (Sheehan et al., 1998) and Structured Clinical Interview for the DSM-IV Axis II (SCID-II (First et al., 1997). DSM-IV diagnosis was not exclusionary as the DNS seeks to establish broad variability in multiple psychiatrically-relevant behavioral phenotypes. Following quality control procedures (Supplementary Material), the final sample consisted of 308 non-Hispanic European/European-American participants (mean \pm SD; age=19.70 $\pm 1.24 ; 148$ males; 63 with DSM-IV Axis I disorder; Table 2). We restricted our sample to non-Hispanic European/European-Americans because the variants included in our profile have been predominantly characterized among samples of European ancestry. European ancestry was determined via self-report and confirmed through ancestrallyinformative principal components (see below).

\subsection{Assessment of Early Life Stress and Psychological Symptoms}

A battery of self-report questionnaires was used to assess past and current experiences and behavior as well as symptoms of psychopathology (e.g., depression, anxiety). The retrospective Childhood Trauma Questionnaire (CTQ; (Bernstein et al., 2003) was used to assess emotional, physical, and sexual abuse as 


\section{DIIORIO HPA BIOLOGICALLY-INFORMED MULTILOCUS PROFILE 6}

well as emotional and physical neglect before the age of 17 to measure ELS (Bernstein et al., 2003; Scher et al., 2001). The 77-item Mood and Anxiety Symptom Questionnaire (MASQ; (Watson et al., 1995) was used to measure symptoms common to depression and anxiety (general distress depression, general distress anxiety) as well as anxiety-specific and depression-specific symptoms (anxious arousal, anhedonic depression), providing additional symptom discrimination between depression and anxiety (Watson et al., 1995).

\subsection{Genotyping and HPA Axis Biologically Informed Multilocus Profile Score (BIMPS)}

DNA was isolated from saliva derived from Oragene DNA self-collection kits (DNA Genotek) customized for 23andMe (www.23andme.com). DNA extraction and genotyping were performed in collaboration with 23 andMe by the National Genetics Institute (NGI), a CLIA-certified clinical laboratory and subsidiary of Laboratory Corporation of America. One of two different Illumina arrays, the HumanOmniExpress or HumanOmniExpress-24, which each also had custom content was used to provide genome-wide SNP data. All genotypes used in analyses were directly typed on each array: FKBP5 rs1360780, CRHR1 rs110402, and NR3C2 rs5522 and rs4635799 (call rates >97\%; HWE ps > 0.21 within the European American subsample). PHASE (Stephens et al., 2001) was used to generate MR haplotypes (van Leeuwen et al., 2011); in all cases posterior probability was $>99 \%$. Eigenstrat was used to generate ancestrally-informative principal components (PCs; (Price et al., 2006) across the entire DNS sample (all ethnicities). K-means cluster plotting and visual inspection of the top 10 components revealed that the top 5 principal components account for divergent ancestral groups within the sample and any outliers (6 SD divergence were excluded as well as those not reporting European ancestry). Subsequently, eigenstrat was again run among individuals reporting European/European-American ancestry to generate components for this specific sample. 


\section{DIIORIO HPA BIOLOGICALLY-INFORMED MULTILOCUS PROFILE 7}

An additive biologically-informed multilocus profile score (BIMPS (Nikolova et al., 2011) was constructed using 2 SNPS (FKBP5 rs1360780 and CRHR1 rs110402) and 1 haplotype (NR3C2 rs5522/NR3C2 rs4635799) within HPA axis-related genes that have been functionally associated with differential HPA axis response and recovery (Table 1; for more details, see Supplementary Material). Across all loci, genotypes associated with relatively "high," "intermediate," and "low" HPA axis response or feedback impairment, were assigned a score of 2,1 , or 0 , respectively, due to evidence of additive associations with HPA axis function for each included polymorphism/haplotype (Table 1). Subsequently scores were summed across loci producing each individuals HPA axis BIMPS score. A higher BIMPS reflects an HPA axis that is overactive and/or has impaired negative feedback. BIMPS ranged from 0-6 and were normally distributed.

Our profile was developed by considering published research examining associations between genetic variation within the canonical HPA axis (i.e., CRHR1, CRHR2, CRHBP, FKBP5, NR3C1, NR3C2) and direct indices of HPA axis function (e.g., cortisol; Table 1). SNPs/haplotypes with at least 2 published studies linking them to measured HPA axis function (i.e., not a disorder associated with HPA axis dysregulation) and with minor allele frequencies greater than $5 \%$ were included in analyses. For each gene, we selected one SNP/haplotype for inclusion in the BIMPS to allow for an equal weighting of gene influence and to minimize inflation caused by linkage disequilibrium. If more than one polymorphism within a gene has been associated with HPA axis function, we selected the polymorphism that has been more extensively characterized (e.g., FKBP5 rs1360780) or studied (e.g., CRHR1 rs110402). If two polymorphisms were similarly well-defined, we used the polymorphism included in our microarray (e.g., CRHR1 rs242929 was not included in our microarray, though CRHRI rs110402 also has one more publication regarding its function). Additionally, if neither the SNP nor a proxy for that SNP were available in our microarray, we were unable to include the SNP in our profile, even if it has been previously associated with indices of HPA axis function (e.g., NR3C1 rs6195 (Kumsta et al., 2007; Wust, 


\section{DIIORIO HPA BIOLOGICALLY-INFORMED MULTILOCUS PROFILE 8}

2004) and NR3C1 rs41423247 (Kumsta et al., 2007; van Rossum et al., 2003; Wust, 2004). For NR3C2 no other polymorphisms have been associated with HPA axis function to our knowledge. Further, though $C R H B P, C R H R 2$ and $N R 3 C 1$ are within the canonical HPA axis, polymorphisms from these genes were not included in the profile because there were; no genetic variants linked to HPA axis function in at least 2 studies (i.e., $C R H R 2$ ), no association reported within a European/European American sample (i.e., CRHBP; (Binder et al., 2010), or no other genetic variant associated with HPA axis function with a minor allele frequency $>5 \%$ (e.g., NR3C1 rs56149945, rs6189) included on our array. By constraining the profile to genetic variation within the canonical HPA axis, rather than genetic variance that may indirectly affect the HPA axis and/or amygdala function (e.g., serotonin-related polymorphisms; (Gotlib et al., 2008), this profile provides an additive index of polygenic variation in the HPA axis associated with its function.

\subsection{BOLD fMRI paradigm}

Amygdala reactivity to threat-related stimuli was assessed with an emotion face-matching challenge paradigm that consistently elicits robust amygdala reactivity (Ahs et al., 2013). The fMRI paradigm consists of 4 perceptual face-matching blocks interleaved with 5 sensorimotor control shape-matching blocks (i.e., circles, horizontal and vertical ellipses). Each emotion-specific block consists of 6 facematching trials, in which participants view a trio of faces derived from a standard set (Ekman and Friesen, 1976) of facial affect pictures (expressing angry, fearful, surprised, or neutral emotions), and select which of 2 faces presented on the bottom row of the display matches the target stimulus presented on the top row. In the shape-matching blocks, participants view a trio of geometric shapes and select which of 2 shapes displayed on the bottom matches the target shape presented on top. Each of the 6 face trios is presented for 4 seconds with a variable inter-stimulus interval of 2-6 seconds; total block length is 48 


\section{DIIORIO HPA BIOLOGICALLY-INFORMED MULTILOCUS PROFILE 9}

seconds. Each control block consists 6 shape trios are presented for 4 seconds with a fixed inter-stimulus interval of 2 seconds, comprising a total block length of 36 seconds.

BOLD MRI acquisition and preprocessing information may be found in the Supplementary Material. Following preprocessing, linear contrasts employing canonical hemodynamic response functions were used to estimate task-specific (i.e., Faces > Shapes) BOLD responses for each individual. The primary contrast of "Faces $>$ Shapes" was used to assay bilateral amygdala reactivity to cues that are conditioned social signals to threat in the environment. Individual contrast images (i.e., weighted sum of the beta images) were used in second-level random effects models accounting for scan-to-scan and participant-to-participant variability to determine mean contrast-specific responses using one-sample ttests. A voxel-level statistical threshold of $\mathrm{P}<0.05$, family wise error (FWE) corrected for multiple comparisons across the bilateral amygdala regions of interest (ROIs), and a cluster-level extent threshold of 10 contiguous voxels was applied to these analyses. The bilateral amygdala ROIs were defined using the AAL template from WFU pickatlas (Whitfield-Gabrieli, 2009).

BOLD parameter estimates from clusters within bilateral amygdala ROIs exhibiting a main effect for the "Faces > Shapes" contrast were extracted using the VOI tool in SPM8 (http://www.fil.ion.ucl.ac.uk/spm) and exported for regression analyses in SPSS (v.18). Extracting parameter estimates from clusters activated by our fMRI paradigm, rather than those specifically correlated with our independent variables of interest, precludes the possibility of any correlation coefficient inflation that may result when an explanatory covariate is used to select a ROI. A recent comparison of various analytic approaches commonly used in the imaging genetics literature recommends this approach (Tong et al., 2016).

\subsection{Statistical analysis}




\section{DIIORIO HPA BIOLOGICALLY-INFORMED MULTILOCUS PROFILE 10}

To maintain post-quality controlled data variability while limiting the influence of extreme outliers, data points \pm 3 SDs were winsorized (to 3SDs from the mean; right Faces $>$ Shapes $n=1$, left Faces $>$ Shapes $n=2$, and the CTQ $(n=2)$. All data were mean-centered prior to analyses. Further to reduce skew, CTQ scores were $\log$ transformed. Prior to the computation of any interaction terms, all continuous values were mean centered. However, raw data values are used for display purposes to aid interpretability. Linear regressions tested whether the BIMPS x ELS interaction predicts amygdala reactivity after accounting for main effects and covariates (i.e., sex and the presence of a DSM-IV disorder, ancestrally informative principal component 1 and 2). Further, consistent with recommendations (Baranger et al., 2016; Keller, 2014), we also included interactions between covariates and variables-of-interest (i.e., ELS x sex; ELS x disorder; ELS x PC1; ELS x PC2; HPA axis BIMPS x sex; HPA axis BIMPS x disorder; HPA axis BIMPS x PC1; HPA axis BIMPS x PC2;) as covariates in our model in an attempt to better account for potential confounds. Analyses of depression and anxiety symptoms were conducted in the same manner with the exception that disorder status and its interactions were removed as a covariate due to concerns of collinearity with the outcome measure (i.e., anxiety and depression symptoms). Post-hoc JohnsonNeyman tests from the PROCESS macro (Hayes, 2013) were used to determine the significant transition

points along the moderator of any significant interactions. Holm-Bonferroni sequential FWE correction (Gaetano, 2013) was used to correct for multiple tests of hypothesized neuroimaging phenotypes (2 tests total: i.e., HPA BIMPS x CTQ predicting left and right amygdala reactivity) and FWE-corrected p values are reported. Any findings of potential interest that were not hypothesized (e.g., main effect of HPA axis BIMPS) were corrected for multiple testing correction using false discovery rate (FDR) correction, as we considered such analyses exploratory (Benjamini and Hochberg, 1995; Goeman and Solari, 2014).

\subsubsection{Competitive BIMPS Significance Testing}


Lastly, to test the specificity of any observed associations, competitive significance testing was performed for any results reaching significance levels following multiple test correction in null hypothesis testing. Three sets of autosomal SNPs were extracted that were matched to the original SNPs on risk allele frequency and independence (MR haplotype was treated as a SNP for convenience; risk allele frequency $(\mathrm{RAF})=$ original SNP RAF \pm 0.05 ; between-SNP $\left.\mathrm{r}^{2}<0.003\right) .10,000$ random "BIMPS" were then generated by summing the "risk" alleles (based on frequency) for one SNP from each of the three

matched sets. Each of these presumably non-associated BIMPS were then tested for interactions with ELS to predict any associations surviving multiple testing correction in null hypothesis testing. Empirical p-values were determined by taking the sum of the number of times a random BIMPS $x$ ELS interaction produced a p-value less than the one obtained in the original analyses, divided by the number of random BIMPS tested (10,000).

\subsection{Results}

\subsection{Demographic Associations}

Males met criteria for alcohol abuse more than women, but gender was not associated with any other variables including HPA axis BIMPS and CTQ (Table S1). In the entire sample, CTQ was correlated with the presence of bipolar disorder NOS but not other diagnoses (Table 2).

\subsection{Amygdala Function}

As in prior studies (Ahs et al., 2013), the face matching task reliably elicited bilateral amygdala reactivity (Figure 1). The HPA axis BIMPS x ELS interaction significantly predicted right, but not left, amygdala reactivity (Figure 2; Right: $\beta=0.145, \Delta \mathrm{F}(1,292)=5.814, \Delta \mathrm{R}^{2}=0.019, \mathrm{p}=0.017$, $\mathrm{p}$ - FWE $=0.034$, Table S2; 


\section{DIIORIO HPA BIOLOGICALLY-INFORMED MULTILOCUS PROFILE 12}

Left: $\beta=0.093, \Delta \mathrm{F}(1,292)=2.415, \Delta \mathrm{R}^{2}=0.008, \mathrm{p}=0.121, \mathrm{p}-\mathrm{FWE}=0.121$, Table S3) ${ }^{1}$ Post-hoc JohnsonNeyman tests revealed ELS was only positively coupled with amygdala reactivity among those with relatively high BIMPS (i.e., BIMPS $\geq 4$, the upper $21.4 \%$ of BIMPS values, all ps $<0.05$; Figure 2; alternative plotting is displayed in Figure S1). In addition to surviving multiple testing correction, results also survived competitive BIMPS testing (emp-p=0.016), indicating that the HPA axis BIMPS x ELS interaction predicting right amygdala reactivity to threat is not simply an artifact of summing any 3 random variants of similar frequency. Further, post-hoc tests revealed that both the right basolateral and centromedial amygdala were similarly associated with the HPA axis BIMPS x ELS interaction (Figure S2).

Follow-up tests evaluated whether each individual polymorphism or haplotype interacted with ELS to predict amygdala function (Table 3). In contrast to results from our profile, which survived multiple testing correction, we observed nominally significant or trending interactions between ELS and both FKBP5 rs1360780 and NR3C2 haplotype, but these tests did not survive multiple testing correction for the 6 single SNP/haplotype tests (Table 3). The nominally significant and trending FKBP5 and NR3C2 interactions with ELS were driven by positive correlations between amygdala reactivity and childhood adversity among individuals homozygous for $F K B P 5 \mathrm{~T}$ alleles $(\mathrm{p}=0.10)$ or $N R 3 C 2$ haplotypes $(\mathrm{p}=0.04)$ associated with elevated cortisol, that was absent in other groups (all other $\mathrm{ps}>0.23$ )

\subsection{Psychological Symptoms}

In contrast to our hypotheses, HPA axis BIMPS did not interact with ELS to predict any MASQ subscale (all $\beta<0.041$, all ps $>0.34$ ). However, in addition to unsurprising positive associations between ELS and all

\footnotetext{
${ }^{1}$ Notably, if outliers ( $\mathrm{n}=4$; i.e., data points \pm 3 SDs on CTQ, right, or left amygdala reactivity) are excluded instead of winsorized, results do not differ substantively: Right $\beta=0.142, \Delta \mathrm{F}(1,288)=2.363, \Delta \mathrm{R} 2=0.041, \mathrm{p}=0.019$; $\mathrm{p}$ $\mathrm{FWE}=0.038$ Left: $\beta=0.088, \Delta \mathrm{F}(1,288)=2.178, \Delta \mathrm{R} 2=0.007, \mathrm{p}=0.141$, $\mathrm{p}-\mathrm{FWE}=0.141$. Further, results remain stable to the inclusion of alcohol use scores (AUDIT) and their interactions with predictor variables $(\beta=0.130$, $\left.\Delta \mathrm{F}(1,289)=4.482, \Delta \mathrm{R}^{2}=0.015, \mathrm{p}=0.035\right)$.
} 


\section{DIIORIO HPA BIOLOGICALLY-INFORMED MULTILOCUS PROFILE 13}

anxiety and depressive subscales of the MASQ (all $\beta>0.145$, all $\mathrm{p}<0.01$ ), we observed a significant main effect of HPA axis BIMPS on MASQ anxious arousal $\left(\beta=0.168, \Delta \mathrm{F}=8.95, \Delta \mathrm{R}^{2}=0.028, \mathrm{p}=0.003\right.$, Figure 3; Table S4), but no other MASQ subscale (all $\beta<0.113$, all $p>0.054$; Tables S5-S8). FDR-correction accounting or 8 tests (i.e., 4 main effects of HPA axis BIMPS and 4 tests of HPA axis BIMPS $x$ ELS interactions for all MASQ scales), showed that this effect survived multiple testing correction (pFDR=0.02). Further, follow-up competitive BIMPS testing revealed a significant association (emp$\mathrm{p}=0.0035$ ). Notably, however, the main effect on anxious arousal was not robust to the inclusion of the HPA axis BIMPS x ELS interaction term (Table S4). No significant associations were observed between psychological symptom scores and amygdala function (R: all $\mathrm{rs}<0.044$, all ps $>0.10$; L: all $\mathrm{rs}<0.068$, all ps>0.23).

\subsection{Discussion}

This study adopted a biologically-informed multilocus profile (Nikolova et al., 2011) approach to examine whether functionally-relevant genetic variation within the HPA axis interacts with ELS to predict amygdala function as well as symptoms of anxiety and depression. ELS was positively coupled with amygdala function only among those with relatively high BIMPS (Figure 2). BIMPS were further predictive of anxious arousal, though there was no evidence that this was mediated by amygdala function. These data are consistent with research across species suggesting that heightened HPA axis function and stress exposure may influence neural circuitry critical for behavioral vigilance and promote stress-related psychopathology (Kolber and Muglia, 2009). More broadly, these data suggest that carefully curated genetic sets within defined systems based upon a priori functional associations in a BIMPS framework may usefully contribute to our knowledge of individual differences in brain function and behavior (Nikolova et al., 2011); but see also limitations in 4.3). 


\section{DIIORIO HPA BIOLOGICALLY-INFORMED MULTILOCUS PROFILE 14}

\subsection{Amygdala Function}

Independent lines of research suggest that HPA axis function may moderate ELS-related potentiation of threat-related amygdala reactivity. Elevated levels of endogenous cortisol predict increased amygdala reactivity and behavioral responses to threatening stimuli (Tottenham and Sheridan, 2009) and direct pharmacologic stimulation of the HPA axis heightens threat-specific amygdala reactivity (Henckens et al., 2010). Emerging research is also suggestive of a putative pathway through which ELS predicts individual differences in HPA axis-related methylation as well as its function in childhood, which in turn is associated with indices in HPA function and functional connectivity in adulthood (Bogdan et al., 2016). The present results build upon this literature by showing that ELS-related differences in amygdala function may be dependent on functionally-relevant genetic variation within the HPA axis. While our results were statistically significantly only in the right hemisphere, they approached trend levels of significance in the left with similar directional effects. As such, while effects may potentially be stronger in the right hemisphere, which some evidence suggests is more involved in unconscious emotion processing (Gainotti, 2012), our data do not strongly suggest lateralized effects.

Notably, our HPA axis BIMPS interaction with ELS was associated with right amygdala reactivity following multiple testing correction. While 2 components of our profile (FKBP5 rs1360780 and NR3C2 haplotype) showed nominally significant and trend level interactions in directions consistent with prior research (Bogdan et al., 2016; Holz et al., 2014; White et al., 2012), these associations did not survive correction for multiple testing (Table 3). As such, these results provide initial evidence that BIMPS based on a prioi functional associations may capture system-level polygenic architecture and provide greater predictive utility than single SNP analyses (but see also limitations below). Further, employing a BIMPS approach that is constrained to a single system (e.g., the canonical HPA axis) enables us to understand how variation within this system is associated with differential neural functioning alongside other methods (e.g., pharmacologic manipulation) and provides a resolution more 


\section{DIIORIO HPA BIOLOGICALLY-INFORMED MULTILOCUS PROFILE 15}

consistent with assays of higher order brain function (e.g., system level variation as opposed to single receptor level variation; (Nikolova et al., 2011). Whether amygdala function related to HPA axis genetic variation and ELS go on to predict later psychopathology and related behaviors (e.g., startle) or are mediated by diurnal cortisol levels or challenge-elicited HPA axis reactivity (Binder et al., 2010; Binder et al., 2004; Klok et al., 2011a), (Pagliaccio et al., 2014), requires future research among longitudinal samples at risk for psychopathology that integrate biomarker assessments.

\subsection{Psychological Symptoms}

Consistent with a wealth of research (Green et al., 2010), ELS predicted symptoms of depression, anhedonic depression, anxiety, and anxious arousal. Anxious arousal was further predicted by HPA axis BIMPS, with increased anxious arousal symptoms endorsed by individuals with higher BIMPS; however, this association did not remain following the introduction of the HPA axis BIMPS x ELS interaction term. Unlike prior research (Bogdan et al., 2016), amygdala function was not associated with anxiety or depressive symptomatology. One possibility for this discrepancy is that our sample is composed of relatively high functioning young adults, with limited clinically significant anxiety $(6.8 \%$ met DSM-IV criteria for any anxiety-related disorder). Such high functioning may represent a potential resilience to some of the deleterious effects of stress, thereby uncoupling the link between threat-related amygdala reactivity and anxiety typically observed in clinical populations.

\subsection{Limitations}

It is important to consider the present results in the context of study limitations including cross-sectional study design, lack of endocrine measures, and the limited generalizability of the sample as well as its size. The cross-sectional design prohibits the implementation of longitudinal data analyses within a developmental framework that would allow the concurrent assessment of changes in brain function as well as environmental stress over time. Such research will be particularly important given nonlinear 


\section{DIIORIO HPA BIOLOGICALLY-INFORMED MULTILOCUS PROFILE 16}

amygdala development (Goddings et al., 2014), differential neural and endocrine associations within children and adults (Hanson et al., 2014), and evidence that the duration of ELS may play important roles in amygdala phenotypes (Mccrory et al., 2011). The lack of endocrine measures prevents the testing of hypothesized models in which genetically-related differences in HPA axis function (e.g., cortisol, stimulated gene expression patterns) mediate the relationship between functional HPA axis variation and amygdala function (Bogdan et al., 2016). The generalizability of our sample is limited because our sample is comprised of relatively high functioning college students. In the context of the present study, it is important to consider this limitation with regard to our assessment of ELS. CTQ total scores in this sample (i.e., $\mathrm{M=33.46)}$ are comparable to other community (Scher et al., 2001) and college samples (e.g., UCSD; n=949, M = 35.2 (Wright et al., 2001), but are considerably lower than those typically observed in clinical samples (Schäfer et al., 2007; Watson et al., 2007). However, despite the relatively comparable scores with general population samples, it may be that those who were exposed to elevated ELS in our sample are particularly resilient to its effects. Lastly, our sample is small for a genetic association study, even when considering neural phenotypes. While it has been argued that neural intermediate phenotypes may be associated with larger effects than more distal and heterogeneous collections of behaviors such as psychopathology, emerging research suggests that effect sizes associations between common genetic variation and neural phenotypes are comparable to that of traditional psychiatric diagnoses (Bogdan et al., 2016; Franke et al., 2016).

More broadly, it is important to also consider the benefits and limitations of the large scale study design of the DNS. A clear benefit of this approach is that, unlike smaller single studies designed to explicitly address a single research question, such broad spectrum studies allow for the accumulation of a large well-powered dataset that can be used to address multiple different research questions, including expected small effects of common genetic variation. Further, because many other studies use similar methodology (e.g., HCP; (Barch et al., 2013); Brain Genomics Superstruct Project; (Holmes et al., In 


\section{DIIORIO HPA BIOLOGICALLY-INFORMED MULTILOCUS PROFILE 17}

press); IMAGEN; (French et al., 2015), results can be readily integrated into prior literature with an increased likelihood that additional data may become available for replication attempts. However, alongside these clear benefits, there are also limitations that must be considered. For instance, such large studies often do not have data that may be useful for a particular research question (e.g., indices of HPA axis function), and, with few exceptions (e.g., Grady Trauma Project; (Binder et al., 2004), often rely on samples of convenience (e.g., university students, volunteers) that limit generalizability. Further, such studies often rely on easily and quickly administered assessments; for example, even though the CTQ is a well-used measure that converges nicely with other assessments of ELS, including interviews, it is relatively limited in its scope of ELS assessment in specific ways (e.g., lacking refined estimates of frequency, severity, and the child's relationship to the perpetrator). Collaboration with psychiatric epidemiology (e.g., (Carey et al., 2015; Nelson et al., 2016), non-human animal models (e.g., (Dincheva et al., 2015; Wellman et al., 2013), and molecular genetics (e.g., (Arloth et al., 2015)) may prove particularly useful in addressing these limitations in stress-related research going forward (Hariri and Holmes, 2015). Finally, due to multiple research questions being probed by multiple investigators, such large datasets may be subject to a higher risk of false positive and negative associations. Transparency with regard to prior publications, formal procedures for submitting and vetting proposed analyses, and ultimately, replication in independent or federated samples when possible, will help alleviate this concern.

While the BIMPS approach has multiple strengths including a polygenic approach and reliance on prior literature, it is also faced with challenges (Bogdan et al., in press). This approach is reliant upon prior functional associations with particular polymorphisms, which could reasonably only be employed in a handful of systems. Further, BIMPS approaches assume additivity within a given system that neglects probable epistatic interactions and probable downstream regulatory processes (e.g., receptor downregulation). Lastly, there are a plethora of options to construct different profiles which may heighten false positive concerns (e.g., we opted to constrain our profile to the HPA axis, but one could reasonable 
extend this profile to any variant associated with HPA axis function). Notably, we used criteria to define our profile and previously proposed the profile used in these analyses in a prior publication (Bogdan et al., 2013) (we removed polymorphism rs 10482605 because there were not 2 positive studies associating it with cortisol) and did not test other profiles not reported here. As BIMPS research moves forward it will be important to be mindful of the plethora of options it provides to researchers and to attempt replication and extension in the context of the same genetic profile.

\subsection{Conclusions}

Limitations notwithstanding, the present findings provide novel insight into the relationship between ELS and amygdala function that contributes to a growing literature emphasizing the importance of this pathway in understanding stress-related psychopathology. These results suggest that genetically-conferred differences in HPA axis function may leave individuals vulnerable to ELS-related potentiation of threatrelated amygdala reactivity, which may in turn promote future psychopathology in the context of additional stress exposure (Swartz et al., 2015). Future large longitudinal studies collecting a variety of data including brain function and structure as well as psychopathology symptoms and endocrine function across time are needed. 


\section{References}

Ahs, F., Davis, C.F., Gorka, A.X., Hariri, A.R., 2013. Feature-based representations of emotional facial expressions in the human amygdala. Social cognitive and affective neuroscience.

Arloth, J., Bogdan, R., Weber, P., Frishman, G., Menke, A., Wagner, K.V., Schmidt, M.V., Karbalai, N., Darina, C., Muller-Myhsok, B., Trumbach, D., Wurst, W., Mehta, D., Uhr, M., Klengel, T., Erhardt, A., Drabant, E.M., (PGC), M.D.D.W.G.o.t.P.G.C., Ruepp, A., Hariri, A.R., Binder, E.B., 2015. Genetically determined differences in the immediate transcriptome response to stress predict risk-related brain function and psychiatric disorders.

Baranger, D.A., Ifrah, C., Prather, A.A., Carey, C.E., Corral-Frias, N.S., Drabant Conley, E., Hariri, A.R., Bogdan, R., 2016. PER1 rs3027172 Genotype Interacts with Early Life Stress to Predict

Problematic Alcohol Use, but Not Reward-Related Ventral Striatum Activity. Front Psychol 7, 464.

Barch, D.M., Burgess, G.C., Harms, M.P., Petersen, S.E., Schlaggar, B.L., Corbetta, M., Glasser, M.F., Curtiss, S., Dixit, S., Feldt, C., Nolan, D., Bryant, E., Hartley, T., Footer, O., Bjork, J.M., Poldrack, R., Smith, S., Johansen-Berg, H., Snyder, A.Z., Van Essen, D.C., 2013. Function in the human connectome: task-fMRI and individual differences in behavior. NeuroImage 80, 169-189.

Benjamini, Y., Hochberg, Y., 1995. Controlling the false discovery rate: A practical and powerful approach to multiple testing. Journal of the Royal Statistical Society 57, 289-300.

Bernstein, D.P., Stein, J.A., Newcomb, M.D., Walker, E., Pogge, D., Ahluvalia, T., Stokes, J., Handelsman, L., Medrano, M., Desmond, D., Zule, W., 2003. Development and validation of a brief screening version of the Childhood Trauma Questionnaire. Child Abuse \& Neglect 27, 169190.

Binder, E.B., 2009. The role of FKBP5, a co-chaperone of the glucocorticoid receptor in the pathogenesis and therapy of affective and anxiety disorders. Psychoneuroendocrinology 34 Suppl 1, S186-195.

Binder, E.B., Owens, M.J., Liu, W., Deveau, T.C., Rush, a.J., Trivedi, M.H., Fava, M., Bradley, B., Ressler, K.J., Nemeroff, C.B., 2010. Association of polymorphisms in genes regulating the corticotropin-releasing factor system with antidepressant treatment response. Archives of general psychiatry 67, 369-379.

Binder, E.B., Salyakina, D., Lichtner, P., Wochnik, G.M., Ising, M., Putz, B., Papiol, S., Seaman, S., Lucae, S., Kohli, M.A., Nickel, T., Kunzel, H.E., Fuchs, B., Majer, M., Pfennig, A., Kern, N., Brunner, J., Modell, S., Baghai, T., Deiml, T., Zill, P., Bondy, B., Rupprecht, R., Messer, T., Kohnlein, O., Dabitz, H., Bruckl, T., Muller, N., Pfister, H., Lieb, R., Mueller, J.C., Lohmussaar, E., Strom, T.M., Bettecken, T., Meitinger, T., Uhr, M., Rein, T., Holsboer, F., Muller-Myhsok, B., 2004. Polymorphisms in FKBP5 are associated with increased recurrence of depressive episodes and rapid response to antidepressant treatment. Nat Genet 36, 1319-1325.

Bogdan, R., Salmeron, B.J., Carey, C.E., Agrawal, A., Calhoun, V.D., Garavan, H., Hariri, A.R., Heinz, A., Hill, M., Holmes, A., Kalin, N.H., Goldman, D., in press. Imaging Genetics and Genomics in Psychiatry: A Critical Review of Progress and Potential. Biol Psychiatry.

Bogdan, R., Hariri, A.R., 2012. Neural embedding of stress reactivity. Nat Neurosci 15, 1605-1607.

Bogdan, R., Hyde, L.W., Hariri, A.R., 2013. A neurogenetics approach to understanding individual differences in brain, behavior, and risk for psychopathology. Mol Psychiatry 18, 288-299.

Bogdan, R., Pagliaccio, D., Baranger, D.A., Hariri, A., 2016. Genetic Moderation of Stress Effects on Corticolimbic Circuitry. Neuropsychopharmacology 41, 275-296.

Bogdan, R., Williamson, D.E., Hariri, A.R., 2012. Mineralocorticoid receptor iso/val (rs5522) genotype moderates the association between previous childhood emotional neglect and amygdala reactivity. American Journal of Psychiatry 169, 515-522.

Carey, C., Agrawal, A., Zhang, B., Conley, E., Degenhardt, L., Heath, A., Li, D., Lynskey, M., Martin, N., Montgomery, G., Wang, T., Bierut, L., Hariri, A., Nelson, E., Bogdan, R., 2015. 


\section{DIIORIO HPA BIOLOGICALLY-INFORMED MULTILOCUS PROFILE 20}

Monoacylglycerol lipase (MGLL) polymorphism rs604300 interacts with childhood adversity to predict cannabis dependence symptoms and amygdala habituation: Evidence from an endocannabinoid system-level analysis. J Abnorm Psychol 124, 860-877.

Davis, M., Whalen, P.J., 2001. The amygdala: vigilance and emotion. Molecular psychiatry 6, 13-34. de Kloet, E.R., Joels, M., Holsboer, F., 2005. Stress and the brain: from adaptation to disease. Nat Rev Neurosci 6, 463-475.

Derijk, R.H., van Leeuwen, N., Klok, M.D., Zitman, F.G., 2008. Corticosteroid receptor-gene variants: modulators of the stress-response and implications for mental health. Eur J Pharmacol 585, 492501.

Dincheva, I., Drysdale, A., Hartley, C., Johnson, D., Jing, D., King, E., Ra, S., Gray, J., Yang, R., DeGruccio, A., Huang, C., Cravatt, B., Glatt, C., Hill, M., Casey, B., Lee, F., 2015. FAAH genetic variation enhances fronto-amygdala function in mouse and human. Nat Commun 6, 6395.

Ekman, P., Friesen, W.V., 1976. Measuring Facial Movement. Environmental Psychology and Nonverbal Behavior 1, 56-75.

Essex, M.J., Shirtcliff, E.A., Burk, L.R., Ruttle, P.L., Klein, M.H., Slattery, M.J., Kalin, N.H., Armstrong, J.M., 2011. Influence of early life stress on later hypothalamic-pituitary-adrenal axis functioning and its covariation with mental health symptoms: A study of the allostatic process from childhood into adolescence. Dev Psychopathol 23, 1039-1058.

Federenko, I.S., Nagamine, M., Hellhamme, D.H., Wadhwa, P.D., Wust, S., 2004. The heritability of hypothalamus pituitary adrenal axis responses to psychosocial stress is context dependent. Journal of Clinical Endocrinology \& Metabolism 89, 6244-6250.

First, M.B., Gibbon, M., Spitzer, R.L., Williams, J.B.W., Benjamin, L.S., 1997. Structured Clinical Interview for DSM-IV Axis II Personality Disorders, (SCID-II).

Franke, B., Stein, J.L., Ripke, S., Anttila, V., Hibar, D.P., van Hulzen, K.J., Arias-Vasquez, A., Smoller, J.W., Nichols, T.E., Neale, M.C., McIntosh, A.M., Lee, P., McMahon, F.J., Meyer-Lindenberg, A., Mattheisen, M., Andreassen, O.A., Gruber, O., Sachdev, P.S., Roiz-Santianez, R., Saykin, A.J., Ehrlich, S., Mather, K.A., Turner, J.A., Schwarz, E., Thalamuthu, A., Yao, Y., Ho, Y.Y., Martin, N.G., Wright, M.J., Schizophrenia Working Group of the Psychiatric Genomics, C., Psychosis Endophenotypes International, C., Wellcome Trust Case Control, C., Enigma, C., O'Donovan, M.C., Thompson, P.M., Neale, B.M., Medland, S.E., Sullivan, P.F., 2016. Genetic influences on schizophrenia and subcortical brain volumes: large-scale proof of concept. Nat Neurosci 19, 420431.

French, L., Gray, C., Leonard, G., Perron, M., Pike, G., Richer, L., Séguin, J., Veillette, S., Evans, C., Artiges, E., Banaschewski, T., Bokde, A., Bromberg, U., Bruehl, R., Buchel, C., Cattrell, A., Conrod, P., Flor, H., Frouin, V., Gallinat, J., Garavan, H., Gowland, P., Heinz, A., Lemaitre, H., Martinot, J., Nees, F., Orfanos, D., Pangelinan, M., Poustka, L., Rietschel, M., Smolka, M., Walter, H., Whelan, R., Timpson, N., Schumann, G., Smith, G., Pausova, Z., Paus, T., 2015. Early Cannabis Use, Polygenic Risk Score for Schizophrenia and Brain Maturation in Adolescence. JAMA Psychiatry 72, 1002-1011.

Gainotti, G., 2012. Unconscious processing of emotions and the right hemisphere. Neuropsychologia 50, 205-218.

Gaetano, J., 2013. Holm-Bonferroni sequential correction: An EXCEL calculator, https://www.researchgate.net/publication/236969037_Holm-

Bonferroni_Sequential_Correction_An_EXCEL_Calculator

Goddings, A.L., Mills, K.L., Clasen, L.S., Giedd, J.N., Viner, R.M., Blakemore, S.J., 2014. The influence of puberty on subcortical brain development. Neuroimage 88, 242-251.

Goeman, J.J., Solari, A., 2014. Multiple hypothesis testing in genomics. Stat Med 33, 1946-1978. 


\section{DIIORIO HPA BIOLOGICALLY-INFORMED MULTILOCUS PROFILE 21}

Gotlib, I.H., Joormann, J., Minor, K.L., Hallmayer, J., 2008. HPA axis reactivity: a mechanism underlying the associations among 5-HTTLPR, stress, and depression. Biol Psychiatry 63, 847-851.

Green, J.G., Mclaughlin, K.A., Berglund, P.A., Gruber, M.J., Sampson, N.A., Zaslavsky, A.M., Kessler, R.C., 2010. Childhood Adversities and Adult Psychiatric Disorders in the National Comorbidity Survey Replication I. Archives of General Psychiatry 67, 113-123.

Hanson, J.L., Nacewicz, B.M., Sutterer, M.J., Cayo, A.a., Schaefer, S.M., Rudolph, K.D., Shirtcliff, E.a., Pollak, S.D., Davidson, R.J., 2014. Behavioral Problems After Early Life Stress: Contributions of the Hippocampus and Amygdala. Biological psychiatry, 1-9.

Hariri, A.R., Holmes, A., 2015. Finding translation in stress research. Nat Neurosci 18, 1347-1352.

Hariri, A.R., 2015. Looking inside the disordered brain: an introduction to the functional neuroanatomy of psychopathology.

Hayes, A.F., 2013. Introduction to Mediation, Moderation, and Conditional Process Analysis: A Regression-Based Approach.

Heim, C., Binder, E.B., 2012. Current research trends in early life stress and depression: review of human studies on sensitive periods, gene-environment interactions, and epigenetics. Exp Neurol 233, 102111.

Heim, C., Bradley, B., Mletzko, T.C., Deveau, T.C., Musselman, D.L., Nemeroff, C.B., Ressler, K.J., Binder, E.B., 2009. Effect of Childhood Trauma on Adult Depression and Neuroendocrine Function: Sex-Specific Moderation by CRH Receptor 1 Gene. Front Behav Neurosci 3, 41.

Henckens, M.J., van Wingen, G.A., Joels, M., Fernandez, G., 2010. Time-dependent effects of corticosteroids on human amygdala processing. J Neurosci 30, 12725-12732.

Holmes, A.J., Hollinshead, M., O'Keefe, T.M., Petrov, V.I., Fariello, G.R., Wald, L.L., Fischl, B., Rosen, B.R., Mair, R.W., Roffman, J.L., Smoller, J.W., Buckner, R.L., In press. Brain Genomics Superstruct Project initial data release with structural, functional, and behavioral measures. Scientific Data.

Holz, N.E., Buchmann, A.F., Boecker, R., Blomeyer, D., Baumeister, S., Wolf, I., Rietschel, M., Witt, S.H., Plichta, M.M., Meyer-Lindenberg, A., Banaschewski, T., Brandeis, D., Laucht, M., 2014. Role of FKBP5 in emotion processing: results on amygdala activity, connectivity and volume. Brain structure \& function.

Ising, M., Depping, A.M., Siebertz, A., Lucae, S., Unschuld, P.G., Kloiber, S., Horstmann, S., Uhr, M., Muller-Myhsok, B., Holsboer, F., 2008. Polymorphisms in the FKBP5 gene region modulate recovery from psychosocial stress in healthy controls. Eur J Neurosci 28, 389-398.

Keller, M.C., 2014. Gene x environment interaction studies have not properly controlled for potential confounders: the problem and the (simple) solution. Biol Psychiatry 75, 18-24.

Klengel, T., Mehta, D., Anacker, C., Rex-Haffner, M., Pruessner, J.C., Pariante, C.M., Pace, T.W., Mercer, K.B., Mayberg, H.S., Bradley, B., Nemeroff, C.B., Holsboer, F., Heim, C.M., Ressler, K.J., Rein, T., Binder, E.B., 2013. Allele-specific FKBP5 DNA demethylation mediates gene-childhood trauma interactions. Nat Neurosci 16, 33-41.

Klok, M.D., Giltay, E.J., Van der Does, A.J., Geleijnse, J.M., Antypa, N., Penninx, B.W., de Geus, E.J., Willemsen, G., Boomsma, D.I., van Leeuwen, N., Zitman, F.G., de Kloet, E.R., DeRijk, R.H., 2011a. A common and functional mineralocorticoid receptor haplotype enhances optimism and protects against depression in females. Transl Psychiatry 1, e62.

Klok, M.D., Giltay, E.J., Van der Does, a.J.W., Geleijnse, J.M., Antypa, N., Penninx, B.W.J.H., de Geus, E.J.C., Willemsen, G., Boomsma, D.I., van Leeuwen, N., Zitman, F.G., de Kloet, E.R., DeRijk, R.H., 2011b. A common and functional mineralocorticoid receptor haplotype enhances optimism and protects against depression in females. Translational psychiatry 1, e62.

Kolber, B.J., Muglia, L.J., 2009. Defining brain region-specific glucocorticoid action during stress by conditional gene disruption in mice. Brain research 1293, 85-90. 


\section{DIIORIO HPA BIOLOGICALLY-INFORMED MULTILOCUS PROFILE 22}

Kumsta, R., Entringer, S., Koper, J.W., van Rossum, E.F.C., Hellhammer, D.H., Wüst, S., 2007. Sex specific associations between common glucocorticoid receptor gene variants and hypothalamuspituitary-adrenal axis responses to psychosocial stress. Biological psychiatry 62, 863-869.

Lupien, S.J., McEwen, B.S., Gunnar, M.R., Heim, C., 2009. Effects of stress throughout the lifespan on the brain, behaviour and cognition. Nat Rev Neurosci 10, 434-445.

Mahon, P.B., Zandi, P.P., Potash, J.B., Nestadt, G., Wand, G.S., 2013. Genetic association of FKBP5 and CRHR1 with cortisol response to acute psychosocial stress in healthy adults. Psychopharmacology (Berl) 227, 231-241.

Marquez, C., Nadal, R., Armario, A., 2005. Responsiveness of the hypothalamic-pituitary-adrenal axis to different novel environments is a consistent individual trait in adult male outbred rats. Psychoneuroendocrinology 30, 179-187.

Mccrory, E., Brito, S.A.D., Viding, E., 2011. The impact of childhood maltreatment : a review of neurobiological and genetic factors. 2, 1-14.

Nelson, E.C., Agrawal, A., Heath, A.C., Bogdan, R., Sherva, R., Zhang, B., Al-Hasani, R., Bruchas, M.R., Chou, Y.L., Demers, C.H., Carey, C.E., Conley, E.D., Fakira, A.K., Farrer, L.A., Goate, A., Gordon, S., Henders, A.K., Hesselbrock, V., Kapoor, M., Lynskey, M.T., Madden, P.A., Moron, J.A., Rice, J.P., Saccone, N.L., Schwab, S.G., Shand, F.L., Todorov, A.A., Wallace, L., Wang, T., Wray, N.R., Zhou, X., Degenhardt, L., Martin, N.G., Hariri, A.R., Kranzler, H.R., Gelernter, J., Bierut, L.J., Clark, D.J., Montgomery, G.W., 2016. Evidence of CNIH3 involvement in opioid dependence. Mol Psychiatry 21, 608-614.

Nikolova, Y.S., Ferrell, R.E., Manuck, S.B., Hariri, A.R., 2011. Multilocus genetic profile for dopamine signaling predicts ventral striatum reactivity. Neuropsychopharmacology 36, 1940-1947.

Pagliaccio, D., Luby, J.L., Bogdan, R., Agrawal, A., Gaffrey, M.S., Belden, A.C., Botteron, K.N., Harms, M.P., Barch, D.M., 2014. Stress-system genes and life stress predict cortisol levels and amygdala and hippocampal volumes in children. Neuropsychopharmacology 39, 1245-1253.

Pearson-Fuhrhop, K.M., Dunn, E.C., Mortero, S., Devan, W., Falcone, G., Lee, P., Holmes, A., Hollinshead, M., Roffman, J., Smoller, J., Rosand, J., Cramer, S., 2014. Dopamine genetic risk score predicts depressive symptoms in healthy adults and adults with depression. PLoS ONE 9, e93772.

Price, A., Patterson, N., Plenge, R., Weinblatt, M., Shadick, N., Reich, D., 2006. Principal components analysis corrects for stratification in genome-wide association studies. Nature genetics2 38, $904-$ 909.

Schäfer, I., Reininghaus, U., Langeland, W., Voss, A., Zieger, N., Haasen, C., Karow, A., 2007. Dissociative symptoms in alcohol-dependent patients: associations with childhood trauma and substance abuse characteristics. Comprehensive Psychiatry 48, 539-545.

Scher, C.D., Stein, M.B., Asmundson, G.J., McCreary, D.R., Forde, D.R., 2001. The childhood trauma questionnaire in a community sample: psychometric properties and normative data. Journal of traumatic stress $14,843-857$.

Shackman, A.J., Tromp, D.P., Stockbridge, M.D., Kaplan, C.M., Tillman, R.M., Fox, A.S., 2016. Dispositional negativity: An integrative psychological and neurobiological perspective. Psychol Bull 142, 1275-1314.

Sheehan, D.V., Lecrubier, Y., Sheehan, K.H., Amorim, P., Janavas, J., Weiller, E., Hergueta, T., Baker, R., Dunbar, G.C., 1998. The Mini-International Neuropsychiatric Interview (M.I.N.I.): the development and validation of a structured diagnostic psychiatric interview for DSM-IV and ICD10. Journal of Clinical Psychiatry 59 Supplem, 22-33.

Stephens, M., Smith, N.J., Donnelly, P., 2001. A new statistical method for haplotype reconstruction from population data. American Journal of Human Genetics 68, 978-989. 


\section{DIIORIO HPA BIOLOGICALLY-INFORMED MULTILOCUS PROFILE 23}

Stice, E., Yokum, S., Burger, K.S., Epstein, H., Smolen, A., 2012. Multilocus genetic composite reflecting dopamine signaling capacity predicts reward circuitry responsivity. J Neurosci 32, 1009310100 .

Swartz, J.R., Knodt, A.R., Spenser, R.R., Hariri, A.R., 2015. A neural biomarker of psychological vulnerability to future life stress. Neuron $85,505-511$.

Tong, Y., Chen, Q., Nichols, T.E., Rasetti, R., Callicott, J.H., Berman, K.F., Weinberger, D.R., Mattay, V.S., 2016. Seeking Optimal Region-Of-Interest (ROI) Single-Value Summary Measures for fMRI Studies in Imaging Genetics. PLoS One 11, e0151391.

Tottenham, N., Sheridan, M.A., 2009. A review of adversity, the amygdala and the hippocampus: a consideration of developmental timing. Front Hum Neurosci 3, 68.

Tyrka, A.R., Price, L.H., Gelernter, J., Schepker, C., Anderson, G.M., Carpenter, L.L., 2009. Interaction of childhood maltreatment with the corticotropin-releasing hormone receptor gene: effects on hypothalamic-pituitary-adrenal axis reactivity. Biol Psychiatry 66, 681-685.

van Leeuwen, N., Bellingrath, S., de Kloet, E.R., Zitman, F.G., DeRijk, R.H., Kudielka, B.M., Wust, S., 2011. Human mineralocorticoid receptor (MR) gene haplotypes modulate MR expression and transactivation: implication for the stress response. Psychoneuroendocrinology 36, 699-709.

van Leeuwen, N., Kumsta, R., Entringer, S., de Kloet, E.R., Zitman, F.G., DeRijk, R.H., Wüst, S., 2010. Functional mineralocorticoid receptor (MR) gene variation influences the cortisol awakening response after dexamethasone. Psychoneuroendocrinology 35, 339-349.

van Rossum, E.F.C., Koper, J.W., van den Beld, A., Uitterlinden, A., Arp, P., Ester, W., Janssen, J., Brinkmann, A.O., de Jong, F.H., Grobbee, D., Pols, H., Lamberts, S.W., 2003. Identification of the BclI polymorphism in the glucocorticoid receptor gene: association with sensitivity to glucocorticoids in vivo and body mass index. Clin Endocrinol (Oxf) 59, 585-592.

Velders, F.P., Kuningas, M., Kumari, M., Dekker, M.J., Uitterlinden, A.G., Kirschbaum, C., Hek, K., Hofman, A., Verhulst, F.C., Kivimaki, M., Van Duijn, C.M., Walker, B.R., Tiemeier, H., 2011. Genetics of cortisol secretion and depressive symptoms: a candidate gene and genome wide association approach. Psychoneuroendocrinology 36, 1053-1061.

Watson, D., Weber, K., Assenheimer, J.S., Clark, L.a., Strauss, M.E., McCormick, R.a., 1995. Testing a tripartite model: I. Evaluating the convergent and discriminant validity of anxiety and depression symptom scales. Journal of abnormal psychology 104, 3-14.

Watson, S., Owen, B.M., Gallagher, P., Hearn, A.J., Young, A.H., Ferrier, I.N., 2007. Family history, early adversity and the hypothalamic-pituitary-adrenal (HPA) axis: Mediation of the vulnerability to mood disorders. Neuropsychiatric disease and treatment 3, 647-653.

Wellman, C., Camp, M., Jones, V., MacPherson, K., Ihne, J., Fitzgerald, P., Maroun, M., Drabant, E., Bogdan, R., Hariri, A., Holmes, A., 2013. Convergent effects of mouse Pet-1 deletion and human PET-1 variation on amygdala fear and threat processing . Exp Neurol 250, 260-269.

White, M.G., Bogdan, R., Fisher, P.M., Munoz, K.E., Williamson, D.E., Hariri, A.R., 2012. FKBP5 and emotional neglect interact to predict individual differences in amygdala reactivity. Genes Brain Behav 11, 869-878.

Whitfield-Gabrieli, S., 2009. Artifact Detection and QA Manual.

Wright, K.D., Asmundson, G.J., McCreary, D.R., Scher, C., Hami, S., Stein, M.B., 2001. Factorial validity of the Childhood Trauma Questionnaire in men and women. Depression and anxiety 13, 179-183.

Wust, S., 2004. Common Polymorphisms in the Glucocorticoid Receptor Gene Are Associated with Adrenocortical Responses to Psychosocial Stress. Journal of Clinical Endocrinology \& Metabolism 89, 565-573. 


\section{DIIORIO HPA BIOLOGICALLY-INFORMED MULTILOCUS PROFILE 24}

\section{Funding Sources}

The authors are thankful to Duke Neurogenetics Study staff and participants.

Christina R. Di Iorio and Lindsay J. Michalski are supported by National Institute of General Medical Sciences [T32 GM081739]. Caitlin E. Carey is supported by National Science Foundation [DGE1143954]. Dr. Nadia Corral-Frias is supported by National Institute of Mental Health [T32-MH014677].

Dr. Ahmad R. Hariri receives support through National Institute of Drug Abuse [DA033369 and DA031579]. Dr. Ryan Bogdan receives support from the Klingenstein Third Generation Foundation, McDonnell Center for Systems Neuroscience, and National Institute on Aging [R01-AG045231]. There are no conflicts of interest for any of the contributing authors. The Duke Neurogenetics Study is supported by Duke University and National Institute on Drug Abuse grant [DA03369]. 


\section{Figure Legends}

Figure 1: HPA axis BIMPS x ELS associated threat-related right amygdala reactivity across all participants (Y=-4; Right amygdala: $\max$ voxel: $\mathrm{x}=28, \mathrm{y}=-4, \mathrm{z}=-20, t=2.90, P_{\text {FWE-corr }}=0.002,204$ voxels; Left amygdala: $\max$ voxel: $\mathrm{x}=-22, \mathrm{y}=-6, \mathrm{z}=-18, \mathrm{t}=2.85, P_{F W E-\text { corr }}=0.002,179$ voxels).

Figure 2: An interaction between the hypothalamic-pituitary-adrenal (HPA) axis biologically-informed multilocus profile scores (BIMPS) and early life stress (ELS) predicted right amygdala reactivity. ELS was significantly positively associated with right amygdala reactivity in individuals with high $(\mathrm{t}(308)=-$ 2.04, $\mathrm{p}=0.04)$, but not low $(\mathrm{t}(308)=-1.53, \mathrm{p}=0.13)$ or average $(\mathrm{t}(308)=0.55, \mathrm{p}=0.58)$ BIMPS. Regions of significance from the Johnson Neyman tests are denoted in yellow $(\mathrm{p}<.05)$. BIMPS and ELS were analyzed as a continuous variable; or ease of visualization, we collapsed the ELS into three groupings: low (25-30), medium (31-37), and high (38-60). For alternative plotting and discussion see

\section{Supplemental Figure 1.}

Figure 3: HPA Axis BIMPS predicted elevated anxious arousal $(\beta=0.168, p=0.003)$. BIMPS were analyzed as a continuous measure but are collapsed into low, average and high groupings for visualization. 


\section{DIIORIO HPA BIOLOGICALLY-INFORMED MULTILOCUS PROFILE 26}

Table 1. Selected HPA Axis Polymorphisms, Associations with HPA Axis Function and Psychopathology, and Coding Scheme for HPA Axis Biologically-Informed Multilocus Profile Scores (BIMPS)

\begin{tabular}{|c|c|c|c|c|c|}
\hline ne & SNP & Associations & Genotype $(\mathrm{N})$ & Score & $\begin{array}{l}\text { Conferring } \\
\text { differences in }\end{array}$ \\
\hline CRHRI & rs110402 & $\begin{array}{l}\text { G allele: increased cortisol response to } \\
\text { the DEX/CRH test in severely } \\
\text { maltreated individuals (Tyrka et al., } \\
\text { 2009), especially in men (Heim et al., } \\
\text { 2009), greater peak cortisol response to } \\
\text { a psychosocial stress test and } \\
\text { significant association of genotype x } \\
\text { trait anxiety interaction with higher } \\
\text { baseline cortisol levels (Mahon et al., } \\
\text { 2013). }\end{array}$ & $\begin{array}{l}\text { AA (73) } \\
\text { AG (173) } \\
\text { GG (78) }\end{array}$ & $\begin{array}{l}\text { 0- Low } \\
\text { 1- Med } \\
\text { 2- High }\end{array}$ & \\
\hline NR3C2 & $\begin{array}{l}\text { rs4635799/ } \\
\text { rs5522 }\end{array}$ & $\begin{array}{l}\text { TC and CT haplotypes: lower } \\
\text { mineralocorticoid promoter activity } \\
\text { and increased salivary and plasma } \\
\text { cortisol, plasma ACTH, and heart rate } \\
\text { in response to a psychosocial stress test } \\
\text { (van Leeuwen et al., 2011; van } \\
\text { Leeuwen et al., 2010); TT and TC } \\
\text { were associated with nominally } \\
\text { lowered AUC cortisol compared to CT } \\
\text { (Klok et al., 2011b). }\end{array}$ & $\begin{array}{l}\text { TT/TT (63) } \\
\text { TC/TT (36) } \\
\text { TT/CT (115) } \\
\text { TC/TC (3) } \\
\text { TC/CT (27) } \\
\text { CT/CT (64) }\end{array}$ & $\begin{array}{l}\text { 0- Low } \\
\text { 1- Med } \\
\text { 1- Med } \\
\text { 2- High } \\
\text { 2- High } \\
\text { 2- High }\end{array}$ & \\
\hline$F K B P 5$ & rs1360780 & $\begin{array}{l}\text { T allele: increased FKBP5 expression } \\
\text { leading to impaired negative feedback } \\
\text { in the system due to decreased GR- } \\
\text { cortisol sensitivity (Binder, 2009; } \\
\text { Binder et al., 2004); lower AUC } \\
\text { cortisol levels (Velders et al., 2011); } \\
\text { impaired CORT recovery in response } \\
\text { to a psychosocial stress test (Ising et } \\
\text { al., 2008); significant interaction with } \\
\text { ELS predicted decreases in }\end{array}$ & $\begin{array}{l}\text { CC (165) } \\
\text { CT (133) } \\
\text { TT (27) }\end{array}$ & $\begin{array}{l}\text { 0- Low } \\
\text { 1- Med } \\
\text { 2- High }\end{array}$ & \\
\hline
\end{tabular}


DIIORIO HPA BIOLOGICALLY-INFORMED MULTILOCUS PROFILE 27

methylation, thereby increasing FKBP5

responsiveness to activation (Klengel

et al., 2013). 
Table 2: Sample demographics and associations with HPA Axis BIMPS and CTQ

\begin{tabular}{|c|c|c|c|}
\hline Variable & $\begin{array}{l}\text { N or Mean } \\
\pm \text { Std Dev }\end{array}$ & $\begin{array}{l}\text { Correlation with } \\
\text { BIMPS }\end{array}$ & Correlation with CTQ \\
\hline Age & $19.70 \pm 1.24$ & $\mathrm{r}=0.10, \mathrm{p}=0.08$ & $\mathrm{r}=-0.10, \mathrm{p}=0.08$ \\
\hline Sex (N male) & 148 & $\mathrm{r}=0.06, \mathrm{p}=0.29$ & $\mathrm{r}=-0.03, \mathrm{p}=0.58$ \\
\hline CTQ & $31.18 \pm 6.69$ & $\mathrm{r}=-0.04, \mathrm{p}=0.50$ & - \\
\hline $\begin{array}{l}\text { Any Disorder (covariate used in } \\
\text { primary analyses) }\end{array}$ & $63^{*}$ & $\mathrm{r}=0.03, \mathrm{p}=0.558$ & $\mathrm{r}=0.018, \mathrm{p}=0.752$ \\
\hline $\begin{array}{l}\text { Agoraphobia without history of } \\
\text { Panic Disorder }\end{array}$ & 6 & $\mathrm{r}=0.063, \mathrm{p}=0.27$ & $\mathrm{r}=0.014, \mathrm{p}=0.81$ \\
\hline Alcohol Abuse & 24 & $\mathrm{r}=0.000, \mathrm{p}=1.00$ & $\mathrm{r}=-0.036, \mathrm{p}=0.53$ \\
\hline Alcohol Dependence & 20 & $\mathrm{r}=0.031, \mathrm{p} 0.58$ & $\mathrm{r}=0.025, \mathrm{p}=0.66$ \\
\hline Anorexia Nervosa & 0 & - & - \\
\hline Bipolar I or II & 3 & $\mathrm{r}=0.000, \mathrm{p}=1.00$ & $\mathrm{r}=-0.032, \mathrm{p}=0.58$ \\
\hline $\begin{array}{l}\text { Bipolar NOS (hypomania but no } \\
\text { depression) }\end{array}$ & 3 & $\mathrm{r}=0.059, \mathrm{p}=0.30$ & $\mathrm{r}=0.190, p=0.001^{*}$ \\
\hline Bulimia Nervosa & 2 & $\mathrm{r}=0.096, \mathrm{p}=0.09$ & $\mathrm{r}=-0.056,0.33$ \\
\hline Dysthymia & 0 & - & - \\
\hline Generalized Anxiety Disorder & 8 & $\mathrm{r}=0.048, \mathrm{p}=0.40$ & $\mathrm{r}=-0.037, \mathrm{p}=0.51$ \\
\hline Major Depressive Disorder & 11 & $\mathrm{r}=-0.005, \mathrm{p}=0.93$ & $\mathrm{r}=0.102, \mathrm{p}=0.07 \#$ \\
\hline OCD & 5 & $\mathrm{r}=0.038, \mathrm{p}=0.51$ & $\mathrm{r}=0.047, \mathrm{p}=0.42$ \\
\hline $\begin{array}{l}\text { Panic Disorder (with or without } \\
\text { Agoraphobia) }\end{array}$ & 3 & $\mathrm{r}=0.059, \mathrm{p}=0.30$ & $\mathrm{r}=-0.062, \mathrm{p}=0.28$ \\
\hline PTSD & 0 & - & - \\
\hline
\end{tabular}


DIIORIO HPA BIOLOGICALLY-INFORMED MULTILOCUS PROFILE 29

\begin{tabular}{l|l|l|l}
\hline Social Anxiety Disorder & 3 & $\mathrm{r}=0.000, \mathrm{p}=1.00$ & $\mathrm{r}=-0.037, \mathrm{p}=0.52$ \\
\hline Substance Abuse (cannabis) & 7 & $\mathrm{r}=-0.013, \mathrm{p}=0.82$ & $\mathrm{r}=0.051, \mathrm{p}=0.37$ \\
\hline Substance Dependence (cannabis) & 5 & $\mathrm{r}=-0.030, \mathrm{p}=0.60$ & $\mathrm{r}=0.073, \mathrm{p}=0.20$ \\
\hline
\end{tabular}

The Ns of disorders include comorbid presentations, hence the summation of these does not match the total number of individuals with at least one psychiatric disorder. *It is important to note that the significant association observed with bipolar disorder should be interpreted with caution due to the small number of individuals $(n=3)$ with the diagnosis in our sample. \# While the association between CTQ and depression was trending in a direction consistent with the literature, it was non-significant. This may be due to the limited number of individuals meeting criteria for MDD in our sample $(n=11)$. Continuous indices of depression and anxiety (e.g., MASQ General Distress Depression and Anhedonic Depression), were consistently and significantly correlated with CTQ (GDD: $r=0.243, p=<0.001$; AD $r=0.334 p=$ $<0.001$; GDA: $\mathrm{r}=0.148, \mathrm{p}=0.009$; AA: $\mathrm{r}=0.171, \mathrm{p}=0.003$ ). 
Table 3: Individual HPA Axis SNPs/Haplotype x CTQ interactions predicting amygdala reactivity

\begin{tabular}{|c|c|c|c|c|c|c|c|c|c|c|}
\hline & \multicolumn{5}{|c|}{ Left Amygdala } & \multicolumn{5}{|c|}{ Right Amygdala } \\
\hline & $\beta$ & $\Delta \mathbf{R}^{2}$ & $\Delta \mathbf{F}$ & $\mathbf{p}$ & FDR p & B & $\Delta \mathbf{R}^{2}$ & $\Delta F$ & $\mathbf{P}$ & FDR $p$ \\
\hline FKBP5 x CTQ & 0.022 & $<0.001$ & 0.144 & 0.705 & 1.00 & 0.097 & 0.009 & 2.666 & 0.104 & 0.21 \\
\hline NR3C2 $\times$ CTQ & 0.086 & 0.007 & 1.987 & 0.160 & 0.48 & 0.140 & 0.017 & 5.295 & 0.022 & 0.07 \\
\hline CRHR1 x CTQ & 0.030 & 0.001 & 0.269 & 0.605 & 1.00 & -0.002 & $<0.001$ & 0.002 & 0.967 & 0.97 \\
\hline
\end{tabular}

Note: FDR-corrected p-values represent correction within each SNP across hemispheres. When all are entered simultaneously, all ps $>\mathbf{0 . 1 3 2}$. 


\section{Figure 1}

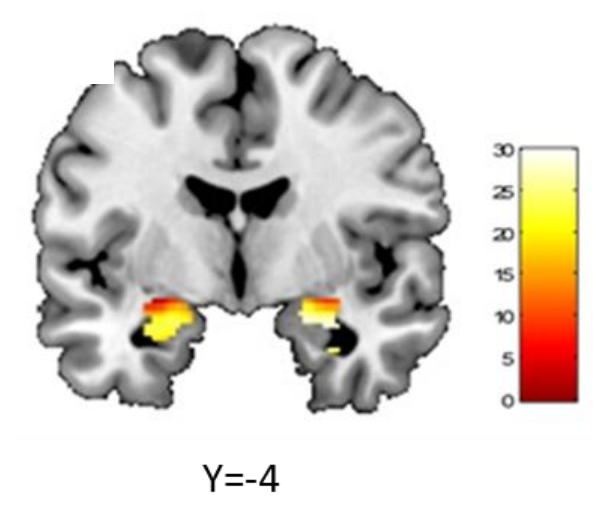

Figure 1: HPA axis BIMPS x ELS associated threat-related right amygdala reactivity across all participants (Y=-4; Right amygdala: $\max$ voxel: $\mathrm{x}=28, \mathrm{y}=-4, \mathrm{z}=-20, t=2.90, P_{F W E-c o r r}=0.002,204$ voxels; Left amygdala: $\max$ voxel: $\mathrm{x}=-22, \mathrm{y}=-6, \mathrm{z}=-18, \mathrm{t}=2.85, P_{F W E-c o r r}=0.002,179$ voxels). 


\section{Figure 2}

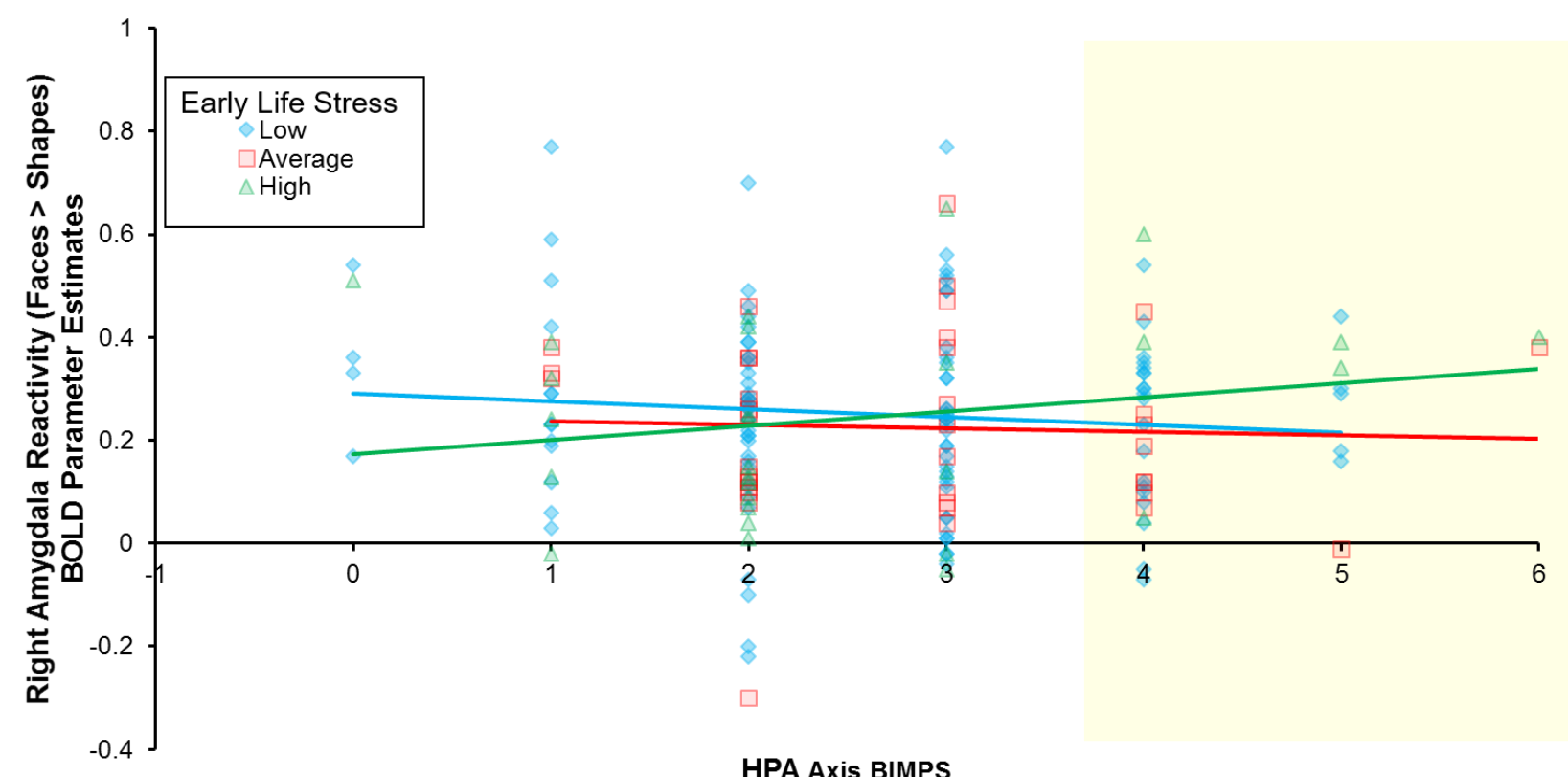

Figure 2: An interaction between the hypothalamic-pituitary-adrenal (HPA) axis biologically-informed multilocus profile scores (BIMPS) and early life stress (ELS) predicted right amygdala reactivity. ELS was significantly positively associated with right amygdala reactivity in individuals with high $(\mathrm{t}(308)=-$ 2.04, $\mathrm{p}=0.04)$, but not low $(\mathrm{t}(308)=-1.53, \mathrm{p}=0.13)$ or average $(\mathrm{t}(308)=0.55, \mathrm{p}=0.58)$ BIMPS. Regions of significance from the Johnson Neyman tests are denoted in yellow $(\mathrm{p}<.05)$. BIMPS and ELS were analyzed as a continuous variable; or ease of visualization, we collapsed the ELS into three groupings: low (25-30), medium (31-37), and high (38-60). For alternative plotting and discussion see

\section{Supplemental Figure 1.}




\section{Figure 3}

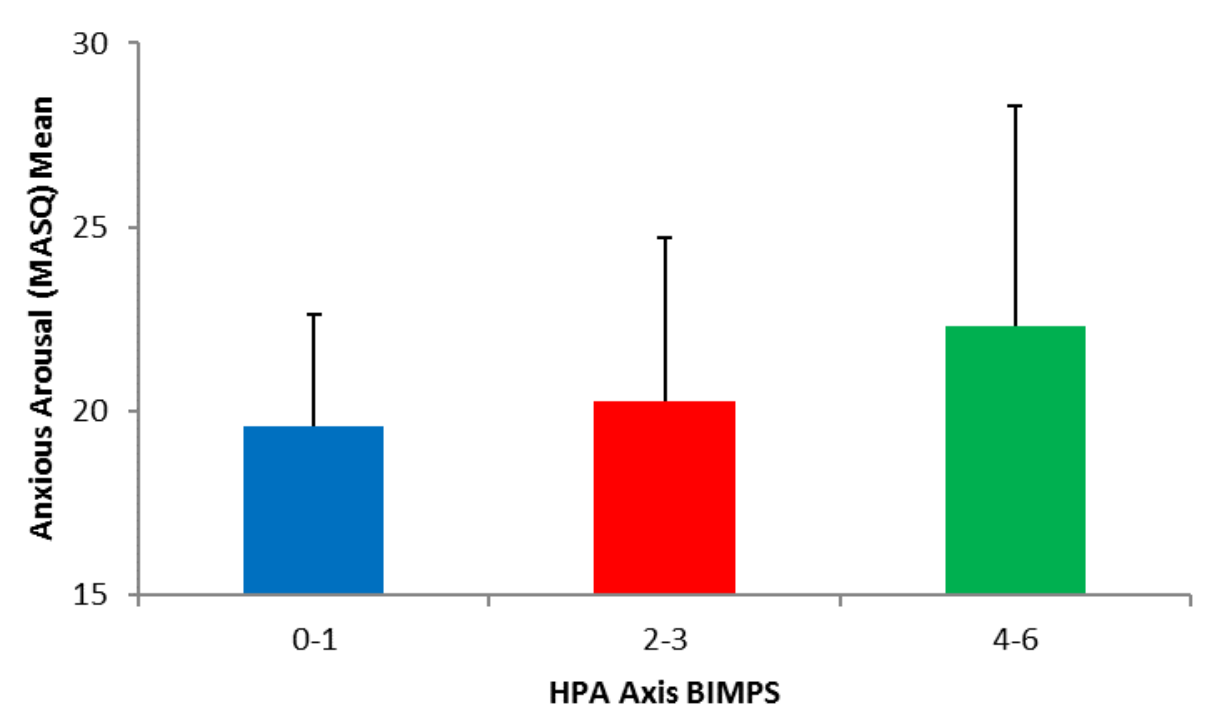

Figure 3: HPA Axis BIMPS predicted elevated anxious arousal $(\beta=0.168, p=0.003)$. BIMPS were analyzed as a continuous measure but are collapsed into low, average and high groupings for visualization. 